\title{
Control of world Albedo by massive salt leaching using the ancientpurpose engineered Qanat-Kariz-Falaj technology to control fractional coverage of crystalline white salt precipitation over vast areas of existing endorheic basins.
}

\section{David Bloch*}

Founder of M.R.Bloch SALT ARCHIVE- Owner of Chemical Engineering consultancy- MBL Separation Engineering, Israel

\begin{abstract}
Huge desert endorheic basins with very substantial areas of flat evaporation pans were once in operation specifically for the precipitation of white crystalline sodium chloride. Maintaining a thin white crust layer of salt during critical hot seasons of the year over these huge areas would increase the world albedo to enable precise control of the total short/long wave reflection, in addition to the high albedo of the polar regions.
\end{abstract}

The surface crust of an inland Sabkha basin typically is made up of layers of salts that have re-crystallized and settled or precipitated during the evaporation process of controlled Qanat system flood waters. Leached Salts dissolve quickly in a desert endorheic basin, and over a short intensely hot period, the process of re-crystallizing the salts can produce purer and more concentrated, layered playa cakes. The dissolved salts leached out of the underlying layers in the vast desert basin flats, are intermittently precipitated back on to the basin surface, predominantly sodium chloride crystals, one after the other leaving the familiar brilliant white salar playa.

The original ancient engineered design of the Qanat and its multiple aligned bore-holes was to control desert endorheic basin flooding without destroying the salt mirror playa or causing erosion of the flat evaporation fields. The Qanat was primarily needed to extract salt, rather than for simple irrigation. Additionally considerable quantities of subsoil brines existing in such basin water tables would ensure brine supplies, as is demonstrated by the new potash plants in the Tarim basin using the ancient Qanat technology.

The grain size of white sodium chloride crystals may be controlled in a similar way to the fine Polar snow crystals which also provide an improved albedo index. By adding 2-Naphtol green accelerator to the brine, the accepted procedure in the salt industry, analternative switch could reduce the albedo and thus increase warming instead of cooling.

Keywords: Salt, precipitation, desert.

\section{Introduction}

Some scientists speak or write of vast environmental engineering projects to offset global warming. Albedo appear in plans and ideas such as seeding clouds, spreading reflective materials on the sea surface, or even launching giant sun umbrellas into space to reflect light away before it can reach the planet.

None of these engineering projects has the potential of a simple canopy of white salt which can be spread quickly and cheaply in a short time period.

The salt "winners" of this ancient industry have for thousands of years relied upon the tides of the sea to fill evaporation pans. This salt industry is probably the only credible witness of historical fluctuations of the eustatic sea level and past climate change. Between the years $100 \mathrm{BCE}$ and $300 \mathrm{AD}$ the Mediterranean sea level is estimated to have risen 1.8 meters. This is a sea level rise indicating global warming similar to present estimated rates of rise. It also is evidence of catastrophic inundation and lack of salt supplies resulting in the development of the Silk road.
The question also has to be asked: If the earth's albedo is not changing then where is the speculated warming energy coming from and can it be controlled?

The mean albedo optical reflective brightness] on a scale of zero to 1 , of planet earth is considered to be approximately 0.30 $(30 \%)$. It is estimated that at albedo $0.42(42 \%)$ planet earth's climate would be in a status similar to that of the last ice age. Albedo for this paper's purpose refers to energy reflected back in the visible spectrum where Kirchoff's Law refers to white crystalline salt's capacity to absorb and emit radiation at a specific wavelength.

If we are to assume that mankind is presently experiencing the upper limit of temperature comfort with the climate and that any further warming would be unacceptable, the following practical use of endorheic deserts is offered as a viable and available possibility of controlling earth's albedo to a safe and comfortable margin of value between these two extremes. Acting as a "dash-pot" to stabilize almost every man-made or 
Citation: Bloch D. Incremental Control of world Albedo by massive salt leaching using the ancientpurpose engineered Qanat-Kariz-Falaj technology to control fractional coverage of crystalline white salt precipitation over vast areas of existing endorheic basins. Environ Risk Assess Remediat. 2017;2(1):1-4

natural eventual tipping point in earth's energy budget leading to climate change, could be controllable.

Estimates have indicated that the recent [10 year ] decrease of a calculated 0.007 albedo has resulted in a global temperature increase of 0.16 degrees Celsius. Whether this is true or not, one might assume that if it was possible to precisely control the earth's albedo all our troubles would "seem so far away". So one can "imagine" that by Increasing or decreasing the world albedo increment by only one or 2 points [+/-] quickly and significantly, it would suffice to react to the future feedback from advanced measuring systems, of man induced or natural climate changes. For example - A recent discovery was made in the Arctic. Dirty snow, scientists found was responsible for much polar and Arctic warming previously blamed on greenhouse gases. Dark soot and ash lightly soiling the pristine snow absorbs about $95 \%$ of the incoming solar radiation, while pristine snow reflects more than 15 times that amount. While spreading a light layer of new snow [ie colouring the Poles a whiter shade], or alternatively spreading a light layer of soot, or increasing cloud reflection could all be possible means of control, they are hardly practical. Neither is spreading an absorbing or reflecting aerosol in the stratosphere to create blocking. All these varied possibilities while perhaps contributing to increasing the albedo to prevent warming, will not contribute to the alternative possibility, a projected cooling of the earth.

Like the albedo of the white Polar regions, the albedo of the Salar de Uyuni is a typical example of salt flats in Bolivia estimated to have an average albedo of 0.69 measured over the total area of $10,000 \mathrm{sq} / \mathrm{km}$ including ultraviolet light. It is even used as the target of satellite calibration due to its flatness and continuity. Thus if one was able to create a number of controlled white surface areas similar to the Salar, with a similar or improved albedo, it would make possible controlling the earth's climate instead of arguing about the causes of climate change.

A confidential pilot project code "SALBEDO" with minimal investment is tentatively in progress, in spite of the fact that existing salt production evaporation pans have been in operation for thousands of years demonstrating the ease of replicating pristine white salt precipitation over vast expanses of potentially high albedo surfaces. The world albedo could be increased or decreased, artificially from an index average presently equal to 0.32 to 0.35 resulting in the controlled decrease of global warming by at least 2-3 C degrees. The albedo could also be reversed since the salt industry today employs accelerators such as 2-Naphthol green dye, to absorb energy and induce faster evaporation. No other available system can presently influence both global warming and global cooling of the earth's energy balance at short notice.

The Qanat Karez water distribution systems are thought to have been inted some 3000 years ago. Thousands of kilometers of tunnels and boreholes were designed and built with very heavy human investment, primarily toleach, dissolve and recrystallize salts - predominantly sodium chloride (Figure 3 ). They were only limited incapacity by the Qanat volumetric capacity watershed flow into the endorheic basins needed to extract the salts. Today we know that in addition nature has continuously supplied these basins with these rich mineral waters, which in many cases lurks only a few meters in the water table below the basin surface. In the Tarim basin a Potash salt production unit is now pumping these brines to produce industrial Potassium fertilizer, using the Qanat Karez technology.

The ancient Qanat water distribution design to leach salt is thought to have operated by controlled flooding of "fields" in endorheic basin flat alluvial areas. The Qanat tunnel volume was seasonally flooded including huge cisterns to provide volumetric capacity. At the appropriate moment the volume of water stored in these cisterns and the tunnels was manually released to "well" and to gush up through multiple bore-holes in the flat basin surface, dissolving the subsoil capillary salts to create a rich brine irrigating the surrounding fields. As the brine became concentrated due to evaporation, the salts re-crystallized and precipitated at their designated point of super saturation. The resulting crust of pure layered salts depended upon the flood controls of the Qanats using leather water bag valves to open and close the Qanat conduits. Thus a controlled shallow brine level in surrounding flat fields optimally dissolved subsoil salt without eroding the flat basin surface to allow brine evaporation and eventually precipitation of a layer of white pristine salt.

\section{Conclusion}

By quickly crystallizing a thin white salt crust canopy over vast areas estimated at 1 million square kilometers, it is estimated the world albedo could be raised by 3 incremental points to maintain a lower global mean temperature (Figure 1). However, this flooding technique and leaching method still primitively employed to produce consumer salt crust $\mathrm{s}$ labs in similar desert basins, is the only foreseeable system which could be also used to prevent global cooling. Just as the new Lop Nor potash plant in the Taklamakan depression, is today producing industrial salts by evaporation so too, could this ancient technology produce a much thinner temporary precipitation of controlled white salt crystallization to cover much larger vast flat alluvial expanses of the many existing endorheic basins. Such a vast area specifically to produce an increased albedo [or alternatively a decreased albedo by shallow flooding the same area with brine colored by 2- Naphthol green dye] would effectively be controllable. By switching seasonally to obtain a reflective white pristine condition at the critical periods of the hot desert climate, it would contribute an incremental controlled additional influence to the existing albedo of polar regions. Implementation of an increase of the albedo by exposing the new white crust or decreasing the albedo by flooding would depend upon achieving a stable reliable real-time feedback measuring system perhaps similar to the CERES or the new Sentinel data system in order to create albedo forcing during relevant seasons of the year. This would require the cooperation of the Shi'a Jafari owners of the ancient Qanat systems still working and situated in the vast existing endorheic basins in the Kavir and Tarim depressions, to extend some of the needed one million square kilometres for modern flooding plant by an international organization. The remaining areas could easily be created from revamping existing endorheic Salar deserts of Australia, Bolivia and of course Utah (Figure 2).

Note: The Ancient QANAT was designed to supply sweet watershed streams to Sabkha endorheic basins, in order to dissolve - re-crystallize, and precipitate new white salt crust with full human process system control. 


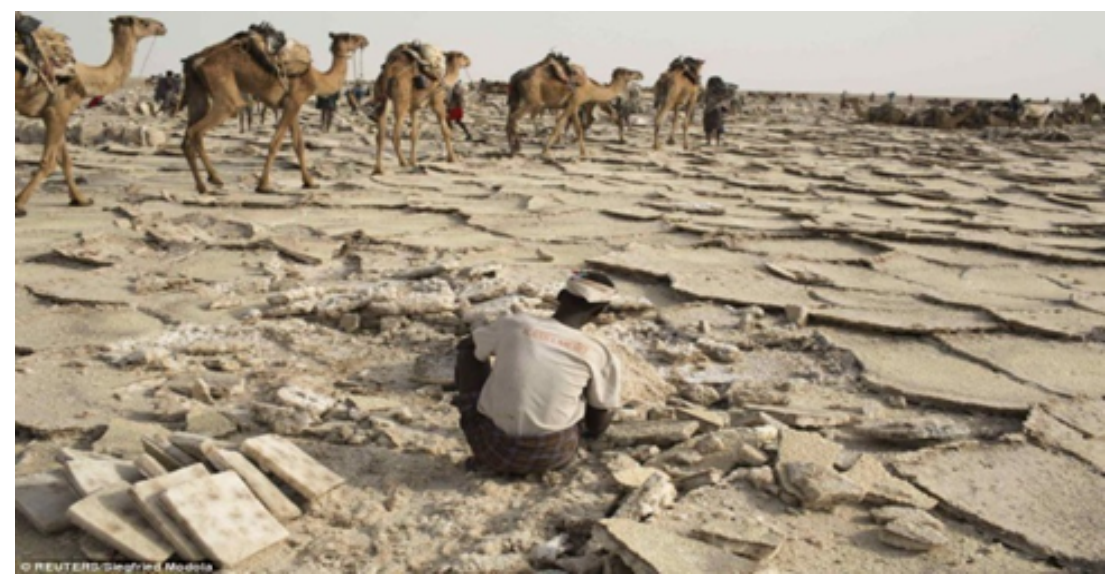

Figure 1. Slabs of salt crust cut and shaped for distribution-Ethiopia.

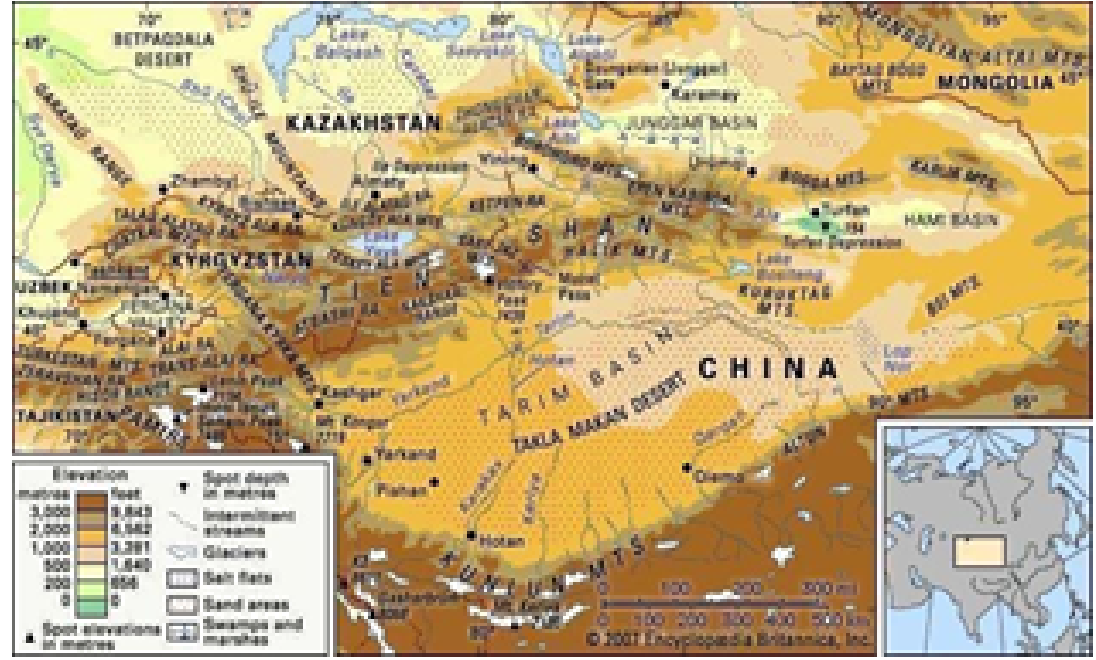

Figure 2. Taklamakan desert-typical of endorheic salt basins Where Qanat systems once produced Salt crust.

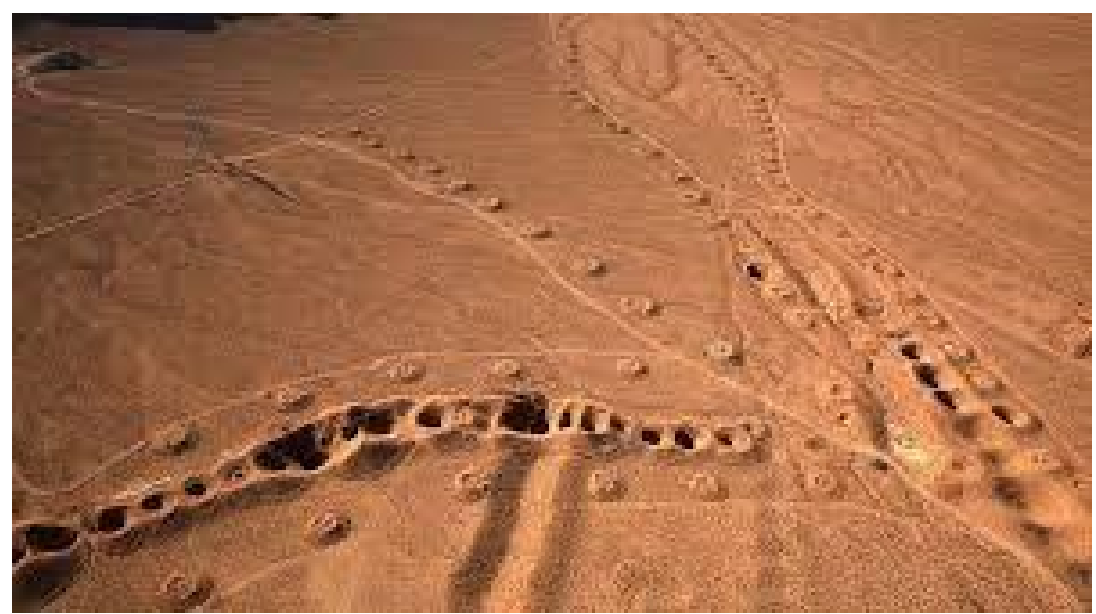

Figure 3. QANAT borehole lines and sink holes between the lines of boreholes where salt has dissolved.

\section{References}

1. Bloch MR. A hypothesis for the change of ocean levels depending on the albedo of the polar ice caps. Paleogeography, paleoclimatology, paleoecology. 1965;1:127-42.

2. Bloch david. Heavy saline streams in salt driven wetlands, abandoned evaporation pans, domes and other salt Deposits as the responsible hydraulic mechanisms causing the disappearance of heavy waste liquids, and other waste Toxic sediments on land and in the ocean proceedings of the 2nd international conference on the ecological importance of solar salt works (ceissa 2009) merida, yucatan, mexico, 26-29 march 2009.

3. Occasional whiteness of the dead sea - web search $\mathrm{mr}$ bloch, hz littman, b elazari-volcani 
Citation: Bloch D. Incremental Control of world Albedo by massive salt leaching using the ancientpurpose engineered Qanat-Kariz-Falaj technology to control fractional coverage of crystalline white salt precipitation over vast areas of existing endorheic basins. Environ Risk Assess Remediat. 2017;2(1):1-4

4. David bloch- qanat karez as ancient salt leaching systems. Emcc 8- the 8th israel technion chemical engineering conf. March 1-2017.

5. The social influence of salt - MR Bloch scientific american n july 1963.
6. Bloch MR. Dust-induced albedo changes of polar ice sheets and glacierization. Journal of glaciology. 1964;5:241-44.

7. Bloch MR, Farkas L, Spiegler KS. Solar evaporation of salt brines. Ind Eng Chem. 1951;43:1544-53.

\section{*Correspondence to:}

David BlochDavid Bloch, founder of M.R. Bloch SALT ARCHIVE

Owner of Chemical Engineering consultancy

MBL Separation Engineering R\&D- Research into Salt

Israel

E-mail: commonsalt@outlook.com 